\title{
Inovasi Media Ajar Bahasa Arab Bagi Orang Tua Didik
}

\author{
Iin Suryaningsih ${ }^{1}$, Hendrawanto $^{2}$ \\ ${ }^{1,2}$ Program Studi Sastra Arab, Fakultas Sastra, Universitas Al Azhar Indonesia, Jalan Sisingamangaraja, \\ Kompleks Masjid Agung Al-Azhar, Kebayoran Jakarta Selatan 12110 \\ Penulis untuk Korespondensi/E-mail: iin.suryaningsih@uai.ac.id
}

\begin{abstract}
Abstrak - Kegiatan Pengabdian kepada Masyarakat berbasis Penelitian yang di beri tema "INOVASI MEDIA AJAR BAHASA ARAB BAGI ORANG TUA DIDIK" ini adalah salah satu bentuk sharing informasi dan sinergi akademik dalam menemukan media ajar bahasa Arab yang tidak hanya cocok bagi pesertanya, namun juga mudah dan menyenangkan. Al-Azhar Centre Purwakarta sebuah lembaga tahsin, tahfidz dan bahasa Arab dibawah Yayasan Andi Azhar berupaya mewadahi minat beberapa kalangan pembelajar termasuk di dalamnya adalah para orang tua/wali murid dari putra putri yang bersekolah di SDIT Al-Bina, Ciseureh Purwakarta. Atas kebutuhan sederhana bahwa sebagai orangtua nantinya mampu mendampingi sang putra menyelesaikan masalah dalam mempelajari bahasa arab di sekolahnya, motivasi kuat para orang tua hebat ini akhirnya menghantarkan mereka menjadi pembelajar bahasa Arab. Semua kegiatan pengabdian ini sepenuhnya bekerja sama dengan AlAzhar Centre, dalam kurun waktu 8 (delapan) bulan rentang November 2016-April 2017, di kompleks SDIT Al-Bina.Metode yang di gunakan dalam penelitian ini bersifat teoretis yaitu metode eksploratif deskriptif
\end{abstract}

Kata Kunci - Inovasi, Media ajar, eksploratif, Al-Azhar Centre,

Abstract - "INNOVATION OF ARABIC LANGUAGE MEDIA FOR PARENTS" This is a form of information sharing and academic synergy in finding Arabic teaching media that is not only suitable for the participants, but also easy and fun. Al-Azhar Center Purwakarta a Tahsin, Tahfidz and Arabic institute under Andi Azhar Foundation seeks to accommodate the interests of some of the learner including the parents / guardians of the sons of daughters who attended SDIT Al-Bina, Ciseureh Purwakarta. For the simple need that as a parent would be able to accompany the son to solve problems in learning Arabic in his school, the powerful motivation of these great parents eventually led them to become Arab learners. All these dedication activities are fully cooperated with Al-Azhar Center, within 8 (eight) months of November 2016April 2017, in the SDIT Al-Bina complex. The method in use in accordance in this research will focus with theoretical methods of descriptive explorative method.

Keywords - Innovation, media teaching, explorative, Al-Azhar Center,

\section{PENDAHULUAN}

$\mathrm{O}$ rientasi terpenting untuk memahami $\mathrm{Al}$ Qur'an dengan baik, adalah dengan mempelajari bahasa arab dengan tidak terbatas pada tingkat akademik formal. Begitu pulakomunitas pembelajarpun akan sangat bervariasi, salah satunya terbentuk dari individu-individu dalam lapisan masyarakat luas yang menyadari kewajiban tersebut untuk terlibat dalam proses pembelajaran bahasa arab seperti hal nya kalangan para orang tua.
Dalam hal keterlibatan diri sebagai pembelajar, Piaget (Henniger, 2013) menekankan bahwa anak-anak secara aktif membangun dunia kognitif mereka sendiri, informasi dari lingkungan tidak begitu saja dituangkan ke dalam pikiran-pikiran mereka [1].Untuk itu perlu pendidikan dan pengasuhan yang tepat terhadap tumbuh kembang anak. Dalam kondisi demikian, orangtua yang memegang peran sangat penting dalam pendidikan dan pengasuhan. Namun, untuk menjadi orangtua 
didik ideal tentu tidak lah mudah.Orang tua di harapkan dapat mengikuti dengan baik seluruh aktivitas putra putrinya, menyelesaikan problematika yang di hadapinya terutama dalam hal kegiatan belajarnya di sekolah. Sebagai upaya memberikan kemudahan belajar untuk anak,orangtua berinisiatif mencari fasilitas belajar tambahan di luar kelas seperti di tempat bimbingan belajar, tentu dengan harapan putra putrinya dapat menguasai beragam kemampuan termasuk dalam hal ini adalah materi bahasa arab.

Al-Azhar Centre sebuah lembaga.dibawah Yayasan Andi Azhar dan berdiri sejak bulan september 2014, saat ini bertempat di Perum Koba blok F1 NO.10 di Jl.KNPI Ciseureuh Purwakarta, tepatnya di komplek SDIT Al-Bina Purwakarta, berupaya mewadahi minat beberapa kalangan di bidang tahsin, tahfidz dan bahasa Arab

Di awali dengan keprihatinan banyaknya masyarakat sekitar Ciseureh Purwakarta yang belum bisa membaca Al-Qur'an, atau yang secara intens mengadakan pembinaan untuk menghafalnya, dan kurangnya minat masyarakat terhadap pengetahuan dan kemampuan bahasa Arab sehingga tidak mampu memahami dan mengamalkan $\mathrm{Al}$ Qur'an dengan optimal, maka Al-Azhar Centre berupaya mengambil peran dan tanggung jawab untuk menjadi fasilitator dari kekurangan tersebut.

Pengamatan penulis terfokus pada minimnya media ajar bahasa Arab yang merupakan media penunjang pembelajaran efektif, dan hal ini di nilai mempengaruhi tingkat keberhasilan pembelajar khususnya bagi level pembelajar seperti para orang tua didik yang sejak awal berharap bisa mendapatkan cara belajar bahasa arab yang tidak hanya mudah, tapi efektif dan menyenangkan bagi mereka dan terlebih bagi putra putri nya nanti.

\section{LANDASAN TEORI}

\section{Media Pembelajaran}

Masyarakat selalu dibentuk oleh hakikat media yang memungkinkan terjadinya komunikasi efektif, daripada oleh isi komunikasi tersebut." kata Marshall (Gani, 4:1988), sebab media atau proses waktu merupakan pola pembentukan kembali ketergantungan antar sosial dan setiap aspek kehidupan personal kita [2]. Hal ini memaksa kita mempertimbangkan dan mengevaluasi kembali setiap pikiran, kegiatan dan setiap institusi terdahulu yang begitu saja kita terima. Prinsip media adalah pesan selalu bergerak dan melihat sesuatu yang terjadi dalam proses perubahan yang sedang berlangsung. Dengan demikian, media lebih terkonsentrasi pada alat atau proses dari pada substansinya, seringkali malah berperan sebagai pengganti substansi tersebut.

Kehadiran media dalam proses belajar bahasa berdasarkan logika pengembangan peran media tersebut, haruslah menunjang keberlangsungan pola berpikir, berbincang dan bertanya pada mahasiswa. Hal ini selaras dengan pendapat Robert (Gani:1988) yang menegaskan pendekatan respon dan analisis (PRA) seyogyanya mendorong: pengembangan proses berpikir, berbincang dan bertanya para peserta didik [2]. Hal ini sesuai dengan kondisi pendidikan Indonesia, pengajar diharapkan dapat secara kreatif menciptakan, mengembangkan, dan mendayagunakan imajinasinya untuk memilih media yang ada dan menciptakan serta mengebangkan media baru dari media lama yang telah dikenal sebelumnya

Strategi dan media yang di gunakan pada pembelajaran pada umumnya yaitu membandingkan karakteristik tema. Jenis media yang digunakan adalah media visual yang dibuat atau dirancang sendiri oleh pengajar/ instruktur bahasa, tetapi materi seperti teks dan gambar yang bervariasi bisa saja diunduh dari internet jika ingin menggunakan materi selain dari buku referensi. Sebut saja pembelajaran mengamati, maka tuntutan yang harusnya di lakukan adalah :

1. Membaca teks tentang karakteristik tema tertentu secara memadai serta mengapresiasinya.

2. Mencermati uraian yang berkaitan dengan tema tertentu

Strategi dan media pembelajaran tersebut di atas, tentu di kaitkan dengan masing-masing objek kajian yang menjadi konsentrasi dan peminatan peserta didik. Dan untuk mencapai hasil belajar bahasa arab yang efektif dan maksimal, lembaga-lembaga pendidikan harus melakukan dua kegiatan, (1) pembelajaran, learning, dan (2) pemerolehan bahasa, language 
acquisition. Pembelajaran akan membentuk keterampilan berbahasa formal, sedangkan pemerolehan bahasa akan membentuk pemakaian bahasa secara non formal. Kedua cara ini menuntut pengajar bahasa mempersiapkan rencana pelaksanaan pembelajaran yang bermutu, yaitu pembelajaran yang dapat terukur dan terkontrol serta adanya komitmen dari semua komponen terkait.

\section{Inovasi dalam Pembelajaran}

Kehadiran dan perkembangan teknologi yang sangat pesat banyak menyebabkan perubahan dramatis dalam segala aspek kehidupan, termasuk pendidikan. Kehadiran teknologi tidak memberikan pilihan lain kepada dunia pendidikan selain turut serta dalam memanfaatkannya. Ini bisa jadi solusi, bisa jadi juga malapetaka bagi generasi masa kini. Pemanfaatan teknologi dalam bidang pengajaran di harapkan dapat meningkatkan kualitas pembelajaran tersebut serta memperluas jaringan pendidikan melalui sarana publikasi dan tersimpan dengan baik, demikianlah inovasi di maknai dalam bidang pendidikan dan pengajaran.(academia.edu).[3]

Jhon Dewey mengemukakan bahwa pendidikan adalah metode dasar dalam melakukan reformasi dan kemajuan sosial :"I believe that education is the fundamental method of social progress and reform". Pendidikan yang dimaksud meliputi pembelajaran dalam tiga faktor,yakni: pengetahuan, keterampilan, dan pembentukan karakter, seperti yang dinyatakan olehnya: "Learning involves, as just said, at least three factors: knowledge, skill and character. Each of these must be studied" (Dewey : 1984) [4].

Dapat juga dikatakan bahwa inovasi pembelajaran merupakan sebuah upaya pembaharuan terhadap berbagai komponen yang diperlukan dalam penyampaian materi pelajaran berupa ilmu pengetahuan dari tenaga pendidik kepada para peserta didik dengan tujuan untuk meningkatkan kualitas pendidikanyang berlangsung. Daya kreativitas dan inovasi secara alamiah telah dimiliki oleh setiap orang. Namun tumbuh dan berkembangnya pada setiap orang ini akan berbeda tergantung dari kesempatan masingmasing untuk mengembangkannya. Pengembangan atau tumbuhnya dengan subur kreativitas dan inovasi pada setiaporang atau sehubungan dengan pekerjaan guru adalah dengan adanya latihan yang berkesinambungan. Latihan ini harus dibarengi pula dengan penanaman sikap dan nilai yang luhur, yaitu sikap seorang ilmuwan dan nilai yang berlandaskan pada IMTAQ.

Inovasi pembelajaran merupakan sesuatu yang penting dan mesti dilakukan oleh guru. Dengan adanya inovasi pembelajaran maka kita sebagai calon guru sebaiknya dapat belajar menciptakansuasana belajar yang menyenangkan, menggairahkan, dinamis, penuh semangat, dan penuh tantangan. Suasana pembelajaran seperti itu dapat mempermudah peserta didik dalam memperoleh ilmu dan guru juga dapat menanamkan nilai-nilai luhur yang hakiki pada peserta didik untuk menuju tercapainya tujuan pembelajaran. Contoh inovasi pembelajaran yang sederhana yaitu membuka dan menutup pelajaran dengannyanyian, membuat materi pelajaran menjadi syair lagu untuk mempermudah menghafal dan mengingat yang didukung dengan media, juga dapat memanfaatkan benda-benda yang ada di lingkungan sekitardalam melakukan inovasi pembelajaran.

Mendidik tidak hanya sekedar mentransfer ilmu kepada peserta didik, tetapi juga membuka pola pikirmereka bahwa ilmu yang mereka pelajari memiliki kebermaknaan untuk hidup mereka sehingga dari ilmu tersebut, mampu merubah sikap, pengetahuan, dan keterampilan mereka menjadi lebih baik.

Penguasaan terhadap materi yang dikelola dan ditampilkan secara profesioal, dari hati dan tanpapaksaan, logis, dan menyenangkan, serta dipadukan dengan pendekatan personalemosional terhadap peserta didik akan menjadikan proses pembelajaran yang ingin dicapai terwujud. Selain itu, pembelajaran juga harus dibuat bervariasi dengan menciptakan suatu metode pembelajaran yang baru atau dengan katalain inovasi.

Berbicara tentang inovasi, sebenarnya kata ini seringkali dikaitkan dengan perubahan, tetapi tidak setiap perubahan dikatakan sebagai inovasi. Inovasi adalah suatu ide, penemuan atau metode yang dirasakan atau diamati sebagai suatu hal yang benar-benar baru bagi 
seseorang yang bersifat relatif.Sedangkan inovasi pembelajaran yang dimaksud disini adalah metode atau kiat seorang guru dalam membelajarkan siswa dengan berbagai tujuan tertentu.Inovasi pembelajaran merupakan sesuatu yang penting dan harus dimiliki atau dilakukan oleh guru. Hal ini disebabkan karena pembelajaran akan lebih hidup dan bermakna. Kemauan guru untuk mencoba menemukan, menggali dan mencari berbagai terobosan, pendekatan, metode dan strategi pembelajaran merupakan salah satu penunjang akan munculnya berbagai inovasi-inovasi baru. Tanpa didukung kemauan dari guru untuk selalu berinovasi dalam pembelajarannya, makapembelajaran akan menjenuhkan bagi siswa. Di samping itu, guru tidak dapat mengembangkan potensi yang dimilikinya secara optimal. Mengingat sangat pentingnya inovasi, maka inovasi menjadi sesuatu yang harus dicoba untuk dilakukan oleh setiap guru. Oleh karena itu, seorang guru harus selalu melakukan inovasi dalam pembelajaran. Langkah yang dapat dilakukan yakni perbaikan cara mengajar guru dengan menggunakan metode baru yang inovatif.

\section{METODE PELAKSANAAN}

\section{Metode}

Metode penelitian dalam kegiatan pengabdian kepada masyarakat yang berbasis penelitian ini disesuaikan dengan tahapan yang dilakukan sepanjang kegiatan ini berlangsung. Terkait bahwa penelitian yang dilakukan adalah berdasarkan studi kasus permasalahan minimnya media ajar yang di pakai oleh para pengajar bahasa arab di Al-Azhar Centre, maka secara teoritis tahap awal metode penelitian yang penulis gunakan adalah metode penelitian eksploratif deskriptif. Melalui metode ini, langkah awal yang penulis lakukan adalah memetakan masalah penelitian secara cermat dan mendalam lalu menguraikankannya, yaitu bagaimana menemukan media ajar yang efektif, mudah dan menyenangkan sebagai bentuk inovasi bagi para orangtua didik sehingga dapat melengkapi dan menunjang keberhasilan pembelajaran bahasa arab putra putrinya.

\section{Tempat dan Waktu}

Kegiatan pengabdian kepada masyarakat berbasis penelitian ini dilaksanakan selama 8 bulan, dalam rentang bulan Nopember 2016-
April 2017. Berlokasi di komplek SDIT AlBina Purwakarta, Perum Koba blok F1 NO.10 di Jl.KNPI Ciseureuh Purwakarta Jawa-Barat.

\section{Teknik Pengumpulan Data}

Dalam penelitian ini digunakan data primer dan data sekunder. Data primer didapatkan dari hasil pengamatan langsung terhadap KBM bahasa Arab di Al-Azhar Centre, sedangkan data sekunder didapatkan dari literatur-literatur yang digunakan untuk penelitian. Metode yang digunakan untuk pengumpulan data pada penelitian ini ialah sebagai berikut:

\section{Observasi}

Metode pengumpulan data dengan observasi merupakan metode yang dilakukan dengan melakukan pengamatan secara langsung terhadap KBM bahasa arab di Al-Azhar Centre. 2. Wawancara

Wawancara merupakan sebuah metode pengumpulan data yang dilakukan untuk memperoleh keterangan untuk tujuan penelitian.

\section{HASIL DAN PEMBAHASAN}

Tingkat kebutuhan media ajar penunjang bagi para pembelajar bahasa arab di Al-Azhar Centre, tentunya sangat tergantung pada tujuan awal terciptanya komunitas ini untuk mempelajari bahasa arab dengan cara yang mudah, menyenangkan dan dalam waktu yang relatif cepat. Hal demikian terbentuk dari motivasi para orang tua tersebut untuk sebisa mungkin mendampingi dan membantu putra putri nya dalam menyelesaikan tugas-tugas materi bahasa arab di sekolah.

\section{Profil Al-Azhar Centre Purwakarta}

Azhar Center berada dibawah Yayasan Andi Azhar dan berdiri sejak bulan september 2014. Saat pertama kali berdiri bertempat di Perum Koba Blok F1 NO.10 di Jl.KNPI Ciseureuh Purwakarta. Dan sekarang bertempat di Jl. Baru Komplek Masjid Hayatul hasanah, Kecamatan/Kabupaten Purwakarta.

\section{Visi dan Misi}

Menjadikan lembag pengembangan Al Qur'an terdepan dibidang Tahsin, Tahfidz dan Bahasa Arab di Purwakarta. Menjadi lembaga yang mencetak sumber daya manusia yang mampu bersaing dan berkompeten serta mempunyai Talaqqy bersama berdasarkan Qiro'ah Hafsh 
serta menjadikan hafizh dan hafizhah dari para lulusannya.

\section{Dasar Hukum \\ "Dan orang - orang yang memberikan kitab, mereka membacanya dengan sebaik - baiknya bacaan, mereka itulah orang yang beriman kepadaNya, dan barang siapa yang mengingkariNya maka mereka itulah orang - orang yang merugi "( $Q S .2: 121$ ) serta" Sebaik - baik diantara kamu sekalian adalah orang yang belajar Al -Quran dan mengajarkannya" (HR.Bukhori).}

Akta Notaris Yayasan Andi Azha rberdasarkan pengesahanMenkumham RI Nomor AHU-0008563.AH.01.12.Tahun 2016 Tangga 15 Februari 2016

\section{Kegiatandan Program Yayasan Andi Azhar}

Yayasan Andi Azhar melakukan pembinaan program berikut ini :

\section{Al-Azhar Centre (Tahsin, Tahfidzdan Bahasa Arab)}

Jadual belajar peserta

Jadwal fleksibel @ 90 menit/ pertemuan. Hal ini cocok bagi peserta yang memiliki kesibukan untuk dapat menggunakan waktu luangnya sebagai waktu belajar Tahsin dan bahasa Arab, khusus untuk tahfidz dikarenakan pesertanya adalah anak-anak maka untuk waktu belajarnya dihari libur sekolah menyesuaikan dengan jadwal sekolah. Peserta bisa request untuk memilih jadwal, yang nantinya akan disesuaikan dengan jadwal pengajar. Pemilihan waktu belajar yang sesuai sangat mendukung tuntasnya pemahaman peserta selama proses belajar mengajar.

\section{Kepengurusan Azhar Center}

Direktur : : H. Andi Mappaenre, Lc.Dipl

Wakil Direktur : Haryadi, S.Pd.I

Sekretaris : DadiSuhadi, S.Pd.I

Bendahara : YeniNuraeni, Lc

\section{Para Pengajar/ Trainer}

1. Ustd. H Andi Mappaere, Lc.Dipl (Alumni Universitas Al Azhar Cairo Mesir)

2. Ustdz. YeniNuraeni, Lc (Alumni Universitas Al Azhar Cairo Mesir)

3. Ustd. Fadli, Lc (Alumni Universitas Al Azhar Cairo Mesir)

4. Ustd. Muhammad Fajri, Lc (Alumni Universitas Al Azhar Cairo Mesir)
5. Ustd. Haryadi, S.Pd.I (Alumni Assyifa Subang)

6. Ustd. DadiSuhadi, S.Pd.I( Alumni Talaqqy bersanad Azhar Center Purwakarta )

7. Ustd. Herman Hadi Al Hafizh (Alumni Al Imarat Bandung)

8. Ustd. Furqan Hakim Al Hafizh (Alumni Al Imarat Bandung)

9. Ustd. Hartoni Al Hafizh (Alumni Al Imarot Bandung)

10.Ustd. Rendi Al Hafizh (Alumni Talaqqy bersanad Azhar Center Purwakarta)

11.Ustd. Wisnu Al Hafizh (Alumni Talaqqy bersanad Azhar Center Purwakarta)

12.Ustd. Rudi Al Hafizh (Alumni Talaqqy bersanad Azhar Center Purwakarta)

13.Ustdz. Cucu Rohaeti (Alumni Talaqqy bersanad Azhar Center Purwakarta)

14.Ustdz. Ika suprihatin (Alumni Talaqqybersanad Azhar Center Purwakarta)

15.Ustdz. Ani Kartika (Alumni Talaqqy bersanad Azhar Center Purwakarta)

16.Ustd. Ahmad Fudholi, Lc (Alumni Universitas Al Azhar Cairo Mesir)

17.Ustd. Apip Nugraha, Lc (Alumni Universitas Al Azhar Cairo Mesir)

18.Ustd. Aded (Imam Mesjid Hayatul Hasanah)

19.Ustd. Husna (Mahasiswa STAI Al AzharPurwakarta)

20.Ustd. TantanBarliana (Alumni Talaqqy bersanad Azhar Center Purwakarta)

21.Ustd. Egi (Alumni AssyifaSubang)

22.Ustd. Dede (Alumni AssyifaSubang)

\section{MajlisTa'lim Al Azhar:}

a. Kajian: Fiqh, Tafsir, UshulFiqh, Haditsdll

b. PPU : Program PengkaderaUlama

c. Mabit : Malam Bina Iman danTaqwa

\section{STAI Al AzharPurwakarta}

Program Studi: a. Bahasa Arab

b. Pendidikan Agama Islam

\section{SMP IT Al AzharPurwakarta}

Analisis: Media ajar Bahasa Arab di AlAzhar Centre, Purwakarta

Secara umum, Sarana dan prasarana belajar di Al-Azhar Centre masih terlihat sangat sederhana dan terbilang klasik. Hal ini mengambil sedikit bagian dari beberapa kondisi yang mempengaruhi proses dan kualitas belajar 
para pembelajar. Buku acuan yang yang menjadi rujukan adalah al-kitab al-Asasi karangan ahli bahasa dari Timur tengah, dengan teks pengantar full berbahasa Arab dengan tanda baca yang tidak lengkap. Sedangkan media ajar yang di gunakan pun sifatnya sangat sederhana: alat peraga berupa miniatur beberapa benda, gambar-gambar, dan melibatkan benda-benda yang ada di sekitar ruang belajar. kesan awal, peserta tidak banyak merespon dengan kondisi demikian, namun hal yang monoton seperti demikian tentu akan membuat mood belajar menurun karena suasana belajar flat, dan kurang interaktif.

\section{Hasil: Inovasi Media ajar}

Berdasarkan aktifitas pengajaran bahasa Arab yang telah berjalan selama ini di Al-Azhar Centre, langkah awal yang penulis lakukan adalah berupaya meyakinkan pihak Al-Azhar bahwa kegiatan pengabdian kepada masyarakat berbasis penelitian ini sama sekali tidak dalam rangka merubah kurikulum dan perangkat pengajaran yang sudah diterapkan sebelumnya dengan perangkat yang lain. Hal sederhana yang dapat penulis katakan adalah bahwa kegiatan ini merupakan salah satu bentuk upaya sharing informasi terkait perangkat pembelajaran bahasa arab khususnya kepada sesama akademisi.

Berikut ini adalah inovasi media ajar bahasa Arab yang penulis tampilkan selama kegiatan pengabdian kepada masyarakat di Al-Azhar Centre ini :

1. LCD dan Speaker aktif: media/perangkat ajar wajib yang harus dimilki oleh AlAzhar Centre untuk menunjang keberhasilan pembelajar bahasa sebagai alat pendukung penguasaan kemahiran mendengar disamping melatih kecermatan peserta dalam menganalisis alur cerita yang di tayangkan.

2. CD dan VCD: media/perangkat ajar yang akan memberikan tema-tema yang sangat variatif, di sesuaikan dengan tujuan pembelajaran

3. Kertas/karton warna: media/perangkat ajar pendukung yang digunakan untuk bermain acak kata/kalimat berbahasa arab agar peserta merasa lebih mudah menghafalkan kosa kata tertentu secara bersama-sama

4. Ruang Multimedia: perangkat ini sebenarnya sangat penting untuk menunjang pembelajaran bahasa Arab. Dengan fasilitas ini, pembelajar akan merasakan nuansa berbeda dari pembelajaran yang pada umumnya tidak di dapatkan di lembaga-lembaga kursus bahasa. Pembelajar dapat meng-ekplor bahan ajar yang variatif melalui multimedia berbasis internet ini.

Selama kegiatan pengabdian ini, penulis mendapat kesempatan membawa peserta ke ruang multimedia yang ada di Yayasan Pondok Pesantren Al-Muhajirin, Purwakarta sebanyak 2(dua) kali, tidak jauh dengan area Al-Azhar Centre, sebagai upaya pengenalan media tersebut kepada peserta.

Dan sebagai upaya lanjutan dari inovasi yang muncul selama kegiatan pengabdian ini berlangsung, al-Azhar Centre akan menindaklanjuti perbaikan sarana dan prasarana belajar termasuk didalamnya adalah media ajar bagi peserta, untuk mewujudkan ketercapaian tujuan pembelajaran yang ingin di raih semua pihak

\section{KESIMPULAN DAN SARAN}

\section{Kesimpulan}

Berdasarkan hasil analisis dan pengolahan data yang telah di lakukan, di peroleh kesimpulan sebagai berikut:

1. Media ajar yang selama ini diterapkan di Al-Azhar centre, tetap akan berjalan sebagaimana biasa, disempurnakan dengan inovasi media lain sebagai bahan pengayaan dan pengalaman belajar peserta seperti media/perangkat ajar yang telah dideskripsikan pada bab hasil dan pembahasan sebelumnya.

2. Inovasi pada media ajar bahasa arab masih harus di gali, dengan upaya memberikan hasil terbaik pembelajaran sesuai dengan tujuan dan kontrak awal belajar yang ingin dicapai oleh peserta.

\section{Saran}

Pengabdian kepada masyarakat berbasis penelitian yang telah dilaksanakan dalam rentang waktu lebih kurang 8 (delapan) bulan ini tentu masih jauh dari hasil sempurna, sekalipun hasil sempurna tersebut adalah harapan semua pihak yang terlibat khususnya 
penulis. Sharing informasi terkait media ajar bahasa arab kepada para pengajar sekaligus peserta/pembelajar di Al-Azhar Centre merupakan salah satu kegiatan untuk menunjang tridharma perguruan tinggi dibidang bahasa arab yang dapat memberikan inovasi baru bagi dunia pembelajaran bahasa arab.

Saran dari penulis terkait kegiatan ini tentu agar uapaya pengayaan informasi terkait perangkat pengajaran yang didukung oleh media-media terkini, dapat ditindaklanjuti kembali pada kegiatan pengabdian di kesempatan lain untuk melakukan penyempurnaan-penyempurnaan.

\section{DAFTAR PUSTAKA}

[1] M.L.Henniger. Teaching Young Children. Fifth Edition. Pearson. 2013
[2] R.Gani.PengajaranSastra IndonesiaRespon dan Analisis-, Jakarta: Depdikbud. 1988

[3] http://www.academia.edu/9984062/INOV ASI_PEMBELAJARAN_BAHASA_ARAB_ Mas Agung. (Diakses Pada 22 Februari 2017)

[4] J. Dewey. 1984. Progressive Education and the Science of Education, dalam TheLater Works, 1925-1953,Volume 3: 1927-1928, Ed: Boydston, Jo Ann, SouthernIllinois University Press, USA, halaman 267-2

[5] M. Akhmadi. Strategi Belajar Mengajar Keterampilan Berbahasa dan Apresiasi Sastra. Malang: YA3.1990

[6] Hasbullah. Dasar-Dasar Ilmu Pendidikan,cet.II, Jakarta: PT. Rajagravindo Persada.2001

[7] Anon. Kamus Besar Bahasa Indonesia : 330. Balai Pustaka. Tahun Terbit, 2002 